\title{
Environmental Transmission Electron Microscopy in an Aberration-Corrected Environment
}

Hansen, Thomas W.; Wagner, Jakob B.

Published in:

Microscopy and Microanalysis

Link to article, DOI:

$10.1017 / \mathrm{S} 1431927612000293$

Publication date:

2012

Document Version

Publisher's PDF, also known as Version of record

Link back to DTU Orbit

Citation (APA):

Hansen, T. W., \& Wagner, J. B. (2012). Environmental Transmission Electron Microscopy in an AberrationCorrected Environment. Microscopy and Microanalysis, 18(4), 684-690.

https://doi.org/10.1017/S1431927612000293

\section{General rights}

Copyright and moral rights for the publications made accessible in the public portal are retained by the authors and/or other copyright owners and it is a condition of accessing publications that users recognise and abide by the legal requirements associated with these rights.

- Users may download and print one copy of any publication from the public portal for the purpose of private study or research.

- You may not further distribute the material or use it for any profit-making activity or commercial gain

- You may freely distribute the URL identifying the publication in the public portal

If you believe that this document breaches copyright please contact us providing details, and we will remove access to the work immediately and investigate your claim. 
Microscopy and Microanalysis

http://journals.cambridge.org/MAM

Additional services for Microscopy and Microanalysis:

Email alerts: Click here

Subscriptions: Click here

Commercial reprints: $\underline{\text { Click here }}$

Terms of use : $\underline{\text { Click here }}$

\section{Environmental Transmission Electron Microscopy in an Aberration- Corrected Environment}

Thomas W. Hansen and Jakob B. Wagner

Microscopy and Microanalysis / Volume 18 / Issue 04 / August 2012, pp 684 - 690

DOI: 10.1017/S1431927612000293, Published online: 12 June 2012

Link to this article: http://journals.cambridge.org/abstract S1431927612000293

How to cite this article:

Thomas W. Hansen and Jakob B. Wagner (2012). Environmental Transmission Electron Microscopy in an Aberration-

Corrected Environment. Microscopy and Microanalysis,18, pp 684-690 doi:10.1017/S1431927612000293

Request Permissions : $\underline{\text { Click here }}$ 


\title{
Environmental Transmission Electron Microscopy in an Aberration-Corrected Environment
}

\author{
Thomas W. Hansen* and Jakob B. Wagner \\ Center for Electron Nanoscopy, Technical University of Denmark, DK-2800 Kgs. Lyngby, Denmark
}

\begin{abstract}
The increasing use of environmental transmission electron microscopy (ETEM) in materials science provides exciting new possibilities for investigating chemical reactions and understanding both the interaction of fast electrons with gas molecules and the effect of the presence of gas on high-resolution imaging. A gaseous atmosphere in the pole-piece gap of the objective lens of the microscope alters both the incoming electron wave prior to interaction with the sample and the outgoing wave below the sample. Whereas conventional TEM samples are usually thin (below $100 \mathrm{~nm}$ ), the gas in the environmental cell fills the entire gap between the pole pieces and is thus not spatially localized. By using an FEI Titan environmental transmission electron microscope equipped with a monochromator and an aberration corrector on the objective lens, we have investigated the effects on imaging and spectroscopy caused by the presence of the gas.
\end{abstract}

Key words: environmental transmission electron microscopy (ETEM), aberration correction, catalysis, scattering

\section{INTRODUCTION}

Already in the early days of transmission electron microscopy (TEM), the idea of imaging samples in the presence of gases and at elevated temperatures was proposed by Ruska (1942) and by Hashimoto and co-workers (Hashimoto \& Naiki, 1968). These first environmental transmission electron microscopes used the concept of differential pumping, i.e., evacuating the microscope column in multiple stages with a pressure drop at each step. This pumping scheme has been extensively developed over the years (Boyes \& Gai, 1997) and is still used on commercial environmental transmission electron microscopes today, e.g., the $\operatorname{Titan}^{\mathrm{TM}}$ environmental transmission electron microscope from FEI Company (Hillsboro, OR, USA). The design Ruska used was based on inserting apertures in the pole pieces to create independently pumped compartments in the microscope column. Hashimoto and Naiki (1968) also used a differential pumping system; however, their approach was slightly different. In their design, the apertures were incorporated as a gas reaction chamber in the specimen holder itself. Whereas the Ruska model has the advantage that it does not impose any restrictions on sample holders, the Hashimoto approach offers the advantage of mobility between microscopes. In both approaches, a sample can be heated while exposed to gases and imaged simultaneously.

Today both approaches are still used. FEI uses a modified objective lens with pressure limiting apertures inserted in the bores of the pole pieces. In contrast, several experimental groups (Creemer et al., 2008; De Jonge et al., 2010) have approached the challenge by adding electron transparent windows above and below the sample in order to confine the gas in a small volume around the sample with a path length through the gas of typically a few tens of

Received October 31, 2011; accepted February 21, 2012

${ }^{*}$ Corresponding author. E-mail: twh@cen.dtu.dk microns. Whereas the latter design allows high pressures, above atmospheric pressure has been shown (Creemer et al., 2008); it limits resolution due the electrons having to travel through the windows. Furthermore, it limits the spectroscopic capabilities of the setup as the generated X-rays have to escape through the windows.

In the beginning of the 21st century, transmission electron microscopes with aberration correctors on either the condenser system or the objective lens were introduced. Such an addition to the microscope column could allow for atomic scale imaging of the surfaces of catalytically active metal nanoparticles in their active state. However, it is still unclear how the presence of gas in the objective lens affects the imaging properties of the microscope. The imaging properties of a transmission electron microscope are optimized for a thin sample located at the eucentric height of the objective lens. In the case of a differentially pumped environmental transmission electron microscope, the solid sample is still located in this plane, but the gas spans the entire pole piece gap. Furthermore, the pressure in the areas surrounding the objective lens is increased.

For environmental transmission electron microscopy (ETEM) experiments the topic of beam effects and beam damage often crops up. Extreme care has to be taken when conducting experiments under intense electron irradiation. Effects of the beam are often more severe at higher pressures mainly due to ionization of gas molecules. The influence of these effects for a given sample can be difficult to predict. A set of reference experiments can help deconvolve the effects caused by the beam from those of other stimuli (Simonsen et al., 2010). Furthermore, the electron beam can be used in a constructive way. Experiments have been carried out in ETEM using the beam for nanolithography in the presence of a precursor gas (Sychugov et al., 2010; van Dorp et al., 2011).

Since the late 1980s and early 1990s, nanoparticles have been an increasing area of research. The specific differences 
in properties, such as free surface energy compared to the bulk counterparts, give them unique characteristics, and they play an increasing role in fields as diverse as catalysis (Więckowski et al., 2003) and medical applications (Salata, 2004). More recently, the nutrition field has also expressed an interest in the field due to the possible toxicity of nanoparticles (Chaudhry et al., 2008; Tiede et al., 2008). The specific properties of nanoparticles also leave them vulnerable to growth processes, known as sintering, especially when exposed to harsh environments such as those found in catalytic converters, for example, where high temperatures and oxidizing environments are often encountered (RostrupNielsen, 1983). Accurate control of the size of nanoparticles is important in many fields. The size of the nanoparticles governs various properties such as optical (Hampe, 1958) and electrical (Herman \& Rhodin, 1966) and also plays a crucial role in the activity of catalysts.

Catalyzed chemical reactions occur on active sites of catalytic material, which often take the form of metal nanoparticles supported on high surface area metal oxides, for example. Over the years, several mechanisms of sintering have been proposed. The two mechanisms mostly agreed upon are Ostwald ripening (Granqvist \& Buhrman, 1976) and particle migration and coalescence (Wynblatt \& Gjostein, 1975; Wanke, 1977). These models have been applied to various catalytic systems (Flynn \& Wanke, 1974), and it has been proposed that the mechanism can be derived from the particle size distribution (Granqvist \& Buhrman, 1976). However, this has been and is still heavily debated (Wanke, 1977). Quite possibly, the first stages of particle coarsening will follow a mechanism different from what occurs when an equilibrium state has been obtained.

Controlling the growth processes of nanoparticles is therefore of the utmost importance, and the processes have been studied widely over the years using various tools, among these are X-ray absorption, X-ray diffraction, and electron microscopy. Whereas the first two techniques have been used extensively to study sintering in situ (Borgna et al., 1992; Rasmussen et al., 2004), ETEM investigations are less common (Simonsen et al., 2010). However, it is the only technique that will provide direct insight into the actual processes.

Most studies on sintering rely solely on postmortem studies, and most of them are based on conventional TEM investigations. Such studies reveal only changes in the size distributions and not through which mechanism these changes occurred. With the advent of in situ TEM, the processes can be investigated as they occur.

One parameter that hampers in situ TEM studies is the effect of the electron beam on the sample. This effect is not well understood and only rarely described in the literature. Howe et al. (2004) carried out an experimental study of the melting behavior of aluminum-silicon alloys, and Gryaznov et al. (1991) calculated temperatures of supported metal nanoparticles exposed to an electron beam as a function of current density. More recently, Simonsen et al. (2010) conducted in situ TEM investigations of model catalytic sys- tems of platinum nanoparticles supported on thin films of alumina. Here they perform a detailed analysis of the effect of the beam, without giving a physical description of the interaction. Interaction of the high-energy electrons with gas and sample can have multiple results, ionization of gases, local heating of the sample, knock-on damage resulting in changes in the nanoparticle morphology, etc. However, even though the fundamentals of these processes are not well understood, important information can be extracted from such in situ experimentation if the effects of the beam are known, at least on a qualitative level.

The aim of this investigation is to study the effects of the gas in the objective lens on the imaging properties of the microscope.

\section{Materials and Methods}

In the present study, an FEI Titan 80-300 environmental transmission electron microscope was used. The microscope uses a three stage differential pumping system allowing a pressure on the order of $10^{2}-10^{3} \mathrm{~Pa}$ in the high pressure region giving a path length through the high pressure region on the order of $7 \mathrm{~mm}$. Under these conditions, the ultrahigh vacuum conditions at the field emission electron source are maintained. Gas is introduced through a port in the objective lens with the flow controlled by digital mass flow controllers. Details of this microscope can be found in Hansen et al. (2010). Furthermore, the microscope features an aberration corrector on the objective lens bringing the resolution to below $1 \AA$.

To monitor the number of scattering events in the gas phase resulting in a loss of acquired electrons, the beam current density on the charge-coupled device (CCD) camera (US1000, Gatan, Inc., Pleasanton, CA, USA) was monitored as a function of gas pressure. The current density was measured using the fluorescent screen that was calibrated against a Faraday cup in the sample plane in a separate experiment carried out in vacuum. Intensities were recorded for various gas species at various pressures. To avoid effects of beam broadening as a result of electrons scattering outside the CCD region, the beam was deliberately kept fairly condensed on the central part of the CCD camera. To establish the intensity of the unperturbed beam, the signal was first measured in vacuum $\left(<10^{-4} \mathrm{~Pa}\right)$ and then up to a value close to the maximum allowed by the differential pumping system. The pressure was measured using a sensor with a displacing metal membrane for pressure measurement (Barocel ${ }^{\circledR}$ 622). After approximately $5 \mathrm{~min}$ at each flow, the pressure reached a stable level and the electron beam intensity could be measured.

To determine the effect of gas in the objective lens on spatial frequency, transmission images of a homogeneous amorphous carbon film were acquired as a function of gas pressure. As the change in gas flow induces a change in height of the amorphous carbon membrane, the height of the sample was mechanically readjusted using the sample stage while keeping the current in the objective lens con- 
stant. This procedure allowed us to rule out variations in the imaging properties as a function of defocus of the microscope itself. The defocus value was determined from the aberration corrector software. Rotational averages were extracted from the Fourier transforms of these images, and the profiles compared. To determine if the electron beam had a damaging influence on the carbon film, an image was acquired after evacuating the gas from the objective lens.

Model catalytic systems were prepared by depositing graphene flakes suspended in ethanol on $3 \mathrm{~mm}$ gold TEM grids coated with a lacey amorphous carbon film. After drying under a heat lamp, $1 \mathrm{~nm}$ of gold was sputter coated onto the grid. The gold coating readily formed nanoparticles with diameters ranging from ca. $1-5 \mathrm{~nm}$.

The grid was placed in a resistive heating holder. After insertion in the microscope, $2 \mathrm{NmL} / \mathrm{min}$ of hydrogen was introduced into the sample region of the microscope. A few seconds after introduction, the pressure was stable at $130 \mathrm{~Pa}$ and the temperature was gradually increased. After a few minutes the temperature was stable at ca. $400^{\circ} \mathrm{C}$. The temperature increase results in spatial drift of the holder due to thermal expansion of the holder assembly, the grid, and the sample. After ca. 15-20 min the drift reached a level where interpretable image sequences could be acquired. To maintain good resolution, the image series were acquired with short acquisition times $(0.5 \mathrm{~s})$, which were subsequently drift corrected using a cross-correlation algorithm.

\section{Results AND Discussion}

Figure 1 shows the intensity recorded on the CCD camera at $80 \mathrm{kV}$ (top) and $300 \mathrm{kV}$ (bottom) as a function of gas pressure in the objective lens for various gas species in the absence of a solid sample. Each curve in the plot has been normalized to the respective intensity recorded in vacuum $\left(<10^{-4} \mathrm{~Pa}\right)$. Assuming that the interaction of electrons on gas molecules scatters the electrons away from the primary beam, the change in intensity can be expressed by a firstorder differential equation. Hence the experimental observations were fitted using an exponential decay. Assuming that the gas in the objective lens can be treated as an ideal gas, the total (elastic plus inelastic) cross section and the mean free paths were calculated for each gas from the equation (using a $7 \mathrm{~mm}$ thick high pressure gas region)

$$
\frac{I}{I_{0}}=\exp \left(-\frac{\sigma P}{R T} \times 7 \times 10^{-3} \mathrm{~m}\right) .
$$

As reported by Yaguchi et al. (2011), the scattering does not only depend on gas pressure, but also on the atomic number of the gas. Whereas the measured intensity only varies little for lighter molecules such as hydrogen and helium, the recorded intensity is less than $30 \%$ of the vacuum value in $1,400 \mathrm{~Pa}$ of argon using $300 \mathrm{kV}$ primary electrons. With $80 \mathrm{kV}$ electrons, the remaining intensity is less than $10 \%$. These observations indicate that the scattering cross section needs to be taken into account when estimating the loss of intensity for a TEM experiment. The scattering of electrons
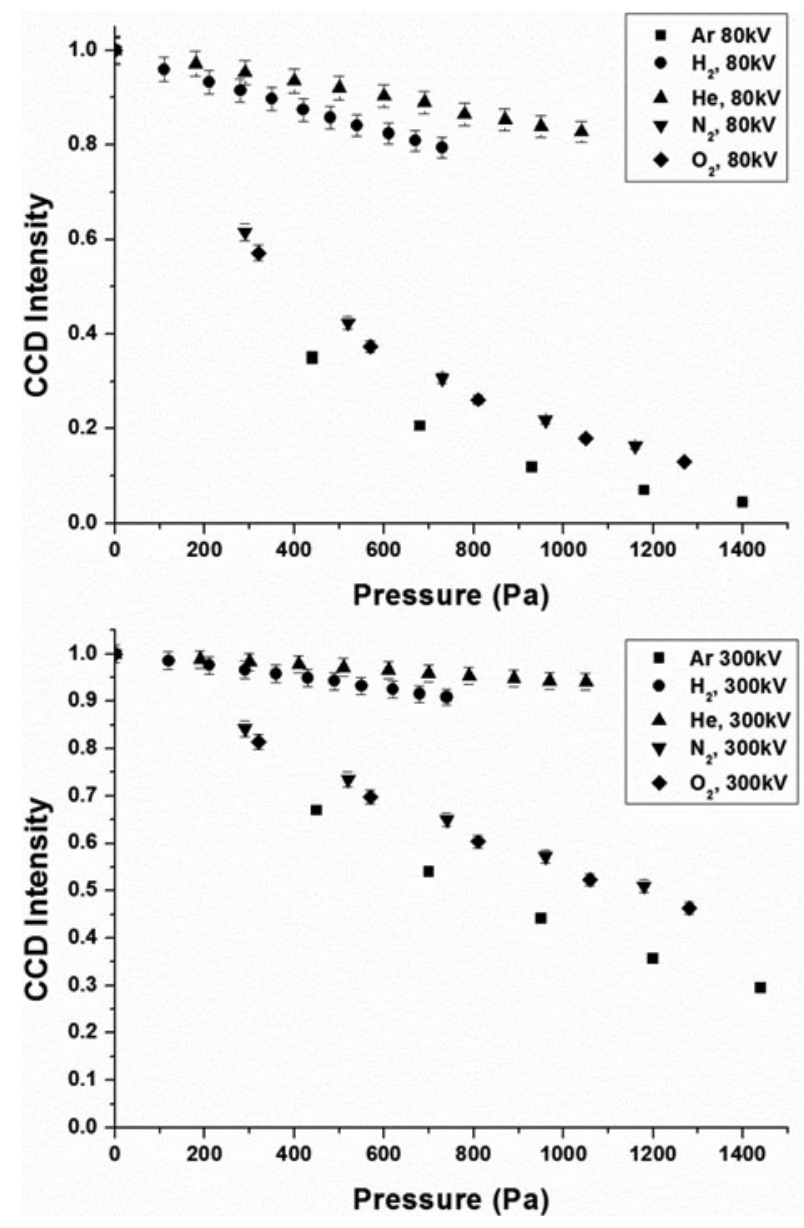

Figure 1. Intensity recorded on the CCD camera as a function of gas pressure for $80 \mathrm{kV}$ (top) and $300 \mathrm{kV}$ (bottom).

off gas molecules follows the atomic number. However, the size of the scattering centers also influences the number of scattered electrons, which is seen as the stronger decay when scattering of hydrogen molecules compared to helium atoms. This is as expected from classical scattering theory. The lighter molecules such as $\mathrm{H}_{2}$ and $\mathrm{He}$ cause only little scattering whereas the largest molecule, Ar, results in more of the primary electrons being scattered far enough to not be recorded.

However, based on these observations, it cannot be concluded that it is only the intensity of unscattered electrons that is measured. Primary electrons can undergo scattering to small angles, both elastic and inelastic, and still contribute to the measured intensity. This can be observed from, for example, electron energy-loss spectroscopy showing low-loss and core-loss features. As the pressure in the objective lens is increased, the ratio between the low-loss features and the zero loss peak increases as expected. The fraction of the total intensity of the inelastically scattered electrons is indicative of the gas pressure in the pole piece gap.

From the Fourier transforms (see Fig. 2) of images recorded from a pristine amorphous carbon film at increasing pressure, the power spectra were extracted (see Fig. 2, 

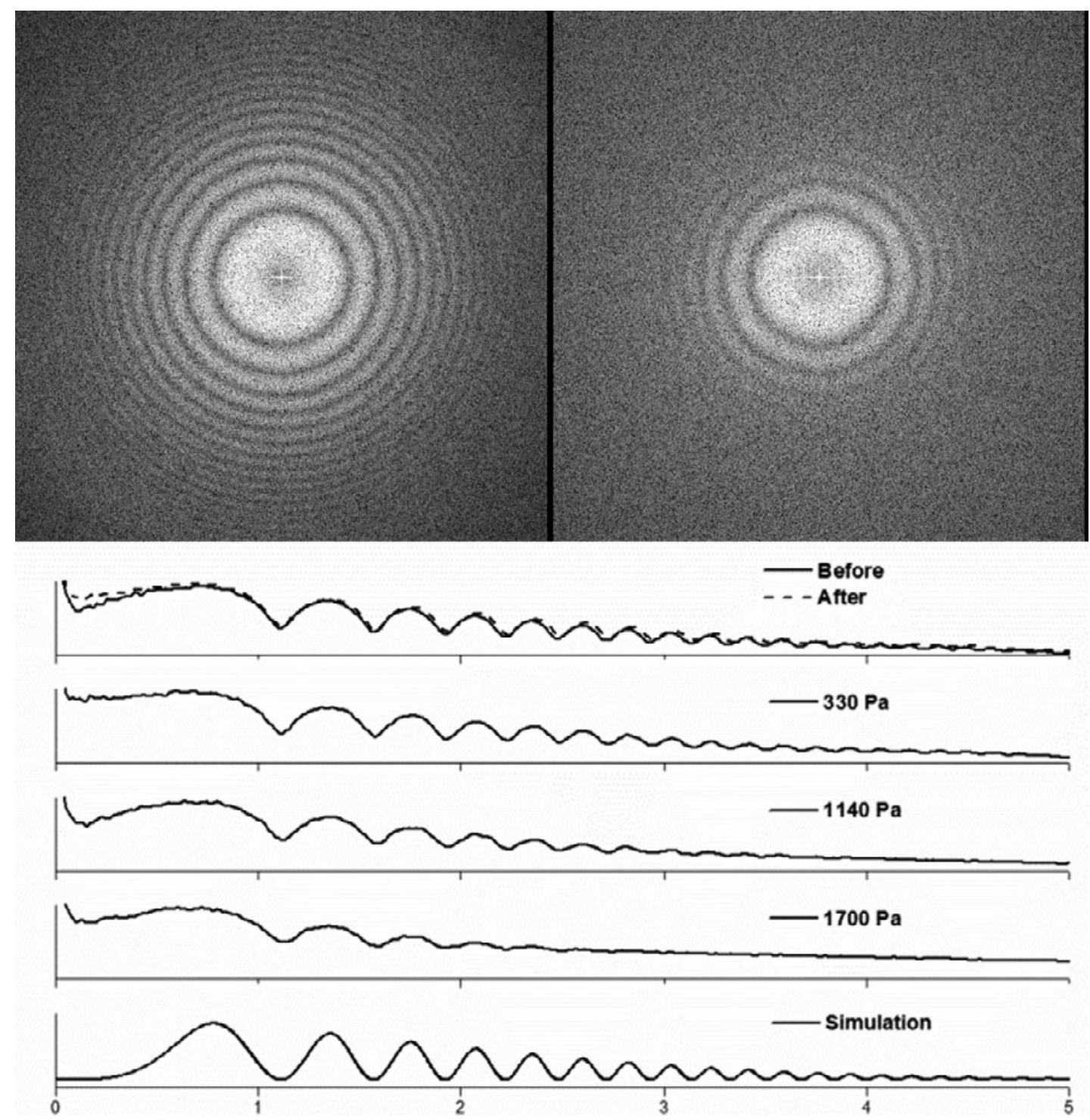

Figure 2. Fourier transforms of images acquired from an amorphous carbon film in vacuum (top left) and at 1,700 Pa argon gas (top right). From the FFTs, the radial intensity has been extracted (bottom). Values at intermediate pressures and a simulation made using CTFExplorer are also included in the plot.

bottom). As described in the Materials and Methods section, the height of the sample was adjusted prior to each acquisition using the sample stage so the calculated defocus value was approximately $410 \mathrm{~nm}$ as measured using the Thon ring measurement in the aberration-corrector software. In the radial intensity profiles of the power spectra, the maxima and minima of the power spectrum are well aligned. Similar observations (not shown here) at $80 \mathrm{kV}$ show a rapid decrease of the contrast transfer already at $330 \mathrm{~Pa}$ argon. In the presence of lighter gas molecules, this dampening is significantly less pronounced. The dampening of the contrast transfer results primarily from inelastic scattering off gas molecules as described by Reimer and Kohl (2008). Scattering off-gas molecules can thus be included in the contrast transfer function as an increase in the angular distribution of the electrons with the added complexity that the scattering occurs not only in the eucentric plane, but through- out the objective lens pole piece gap. However, at relatively low pressures the effect is not detrimental to the image formation. One advantage of the differentially pumped system is that the gas is evacuated from the sample region directly above and below the sample. This provides a centro-symmetric symmetry of the pressure in the sample plane and directional cutoffs are not observed on the fast Fourier transform (FFT). A rigorous analytical derivation of the effects of this scattering is beyond the scope of the present work.

A more severe effect of the presence of gas around the sample is damage on the sample and support film primarily in the form of etching. This effect can be minimized by keeping the beam current density low. For this reason, the current density was deliberately kept low for the present observations, on the order of $1 \mathrm{~A} / \mathrm{cm}^{2}$. The effect on the amorphous film was monitored by recording an image in vacuum after the experiment. The FFT of this image indi- 


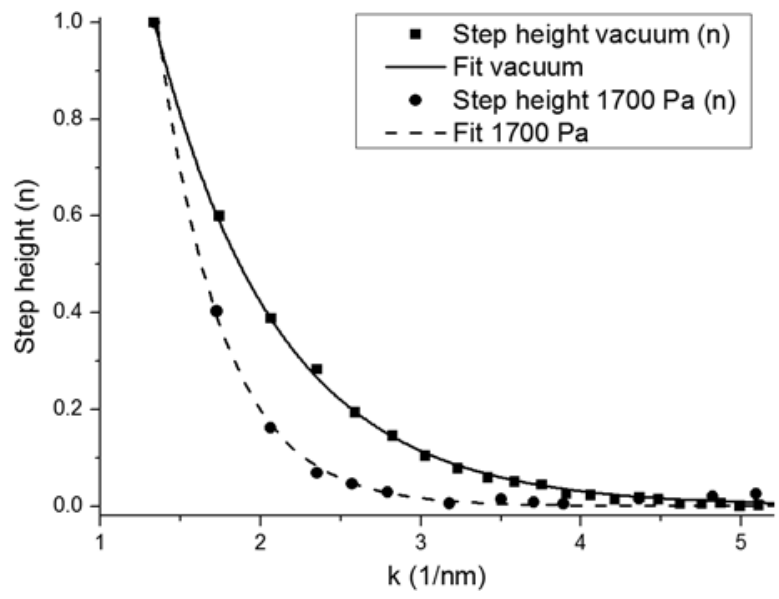

Figure 3. Normalized step height determined from FFTs of images of amorphous carbon film in vacuum and in 1,700 $\mathrm{Pa}$ argon. The data have been fitted using an exponential decay.

cates that the damage sustained by the film was insignificant (see Fig. 2, bottom plot).

Each scattering event causes the electrons to travel at an angle to the optical axis. Assuming that these angles follow a Gaussian distribution, summing over the entire distribution will result in a dampening of the contrast transfer that follows an exponential decay. For a rigorous derivation see Reimer and Kohl (2008). The dampening of the power spectra was fitted by first plotting the normalized peak-topeak intensity as a function of $k$ (see Fig. 3). In the pressure range investigated, the dampening follows an exponential decay as expected.

The optimal conditions provided by the aberrationcorrected environmental transmission electron microscope have been used to investigate the growth processes of gold nanoparticles supported on graphene, a pseudo twodimensional substrate. This system has been chosen to model an industrial catalytic system while limiting some of the complexity offered by technically relevant catalysts.

Most experiments related to catalysis are performed in an atmosphere consisting of lighter molecules than argon. Often the reduction process of transition metal oxides in a hydrogen atmosphere is the topic of investigation. Such experiments can be carried out at reasonably low pressures, often below $500 \mathrm{~Pa}$. As seen from Figure 1 and Table 1, such an environment affects the imaging considerably less than a high pressure argon atmosphere.

Figure 4 shows images of gold particles supported on graphene under vacuum and different hydrogen pressures. In all images the projected surfaces of the gold particles are clearly resolved and interpretable. Even at the highest pressure, no visible deterioration of the image resolution is observed. The (311) planes of gold with a lattice spacing of $1.23 \AA$ are resolved in all three images. Also the graphene substrate is almost invisible as expected from images acquired at low $C_{S}$ and close to zero defocus.

At room temperature, the gold particles are reasonably stable on the graphene flakes. In the presence of the electron beam, they tend to mostly make irregular movements around a fixed site rather than migrate laterally across the substrate, both in vacuum and in the presence of hydrogen. This phenomenon has also been observed when using boron nitride as support material. As the primary energy of the electrons is significantly above the threshold for knock-on damage of graphene sheets (Smith \& Luzzi, 2001; Girit et al., 2009), such motion may be related to restructuring of the graphene substrate rather than inherently related to the dynamics of the gold nanoparticles. The substrate restructuring is also observed in lower magnification image sequences where the graphene sheets as a whole change shape and deteriorate in the presence of the electron beam. Such restructuring can move the gold nanoparticles into direct contact with each other, subsequently resulting in particle coalescence. Even though the influence of the high-energy electrons on the graphene are significantly more pronounced at $300 \mathrm{kV}$ compared to, for example, $80 \mathrm{kV}, 300 \mathrm{kV}$ was chosen due to the detrimental effects on the imaging properties of lowering the acceleration voltage, as shown in Figure 1.

Upon increasing the temperature, the gold nanoparticles become dynamic. When keeping the beam current density reasonably low, observation of coalescence events can be observed without significant damage to the supporting substrate. The graphene substrate in the electron beam seems to be more stable at elevated temperature as also suggested in the literature (Tsetseris \& Pantelides, 2009). In most cases, the gold nanoparticles migrate as crystalline entities across the substrate. As they come into contact, a bridge of material is formed linking the particles together (see Fig. 5). Once the bridge has been formed and atoms can migrate from particle to particle, an equilibrium state is quickly attained. The lattice fringes of both the constituent particles and the resulting particle are resolved throughout the process. The image quality is clearly diminished at elevated temperature. This is due primarily to the drift in the specimen holder, but also to the magnetic field resulting from the heating coil in the heating holder.

Table 1. Scattering Cross Section and Mean Free Paths from Gases Typically Used in the Environmental Transmission Electron Microscope.

\begin{tabular}{lcc}
\hline $\begin{array}{l}\text { Primary Electron } \\
\text { Energy, Gas Specie }\end{array}$ & $\begin{array}{c}\sigma \\
\left(\mathrm{m}^{2}\right)\end{array}$ & $\begin{array}{c}\lambda(500 \mathrm{~Pa}) \\
\left(10^{-3} \mathrm{~m}\right)\end{array}$ \\
\hline $80 \mathrm{keV}, \mathrm{H}_{2}$ & $1.8 \mathrm{E}-22$ & 46 \\
$80 \mathrm{keV}, \mathrm{He}$ & $9.7 \mathrm{E}-23$ & 85 \\
$80 \mathrm{keV}, \mathrm{N}_{2}$ & $8.9 \mathrm{E}-22$ & 9 \\
$80 \mathrm{keV}, \mathrm{O}_{2}$ & $9.1 \mathrm{E}-22$ & 9 \\
$80 \mathrm{keV}, \mathrm{Ar}$ & $1.3 \mathrm{E}-21$ & 7 \\
$200 \mathrm{keV}, \mathrm{N}_{2}$ & $4.1 \mathrm{E}-22$ & 20 \\
$200 \mathrm{keV}, \mathrm{O}_{2}$ & $4.1 \mathrm{E}-22$ & 20 \\
$200 \mathrm{keV}, \mathrm{Ar}$ & $6.0 \mathrm{E}-22$ & 14 \\
$300 \mathrm{keV}, \mathrm{N}_{2}$ & $3.2 \mathrm{E}-22$ & 26 \\
$300 \mathrm{keV}, \mathrm{O}_{2}$ & $3.0 \mathrm{E}-22$ & 28 \\
$300 \mathrm{keV}, \mathrm{Ar}$ & $4.5 \mathrm{E}-22$ & 19 \\
\hline
\end{tabular}




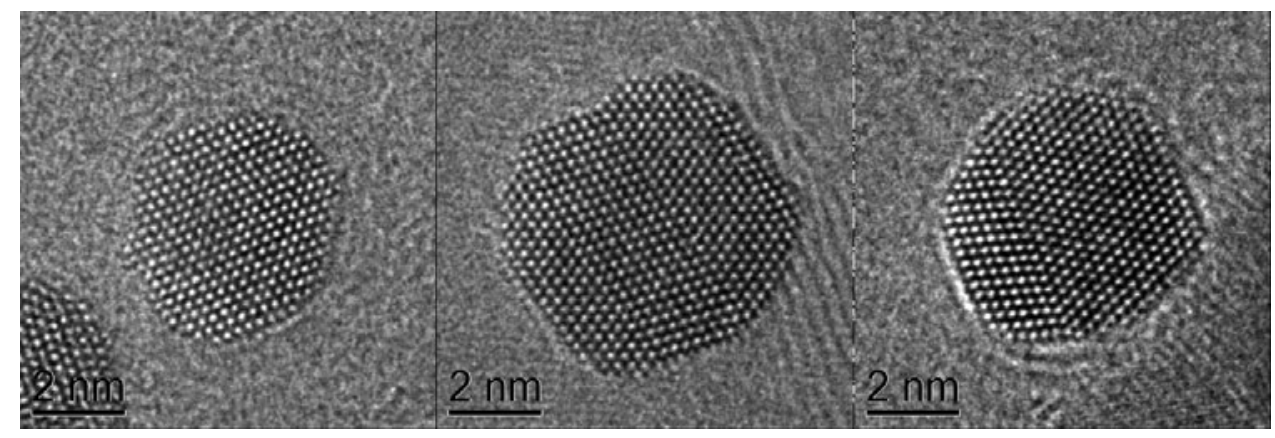

Figure 4. Gold nanoparticles supported on a graphene substrate. The images are (from left to right) recorded in vacuum $\left(10^{-4} \mathrm{~Pa}\right)$, and in $290 \mathrm{~Pa}$ and $430 \mathrm{~Pa}$ of hydrogen, respectively.

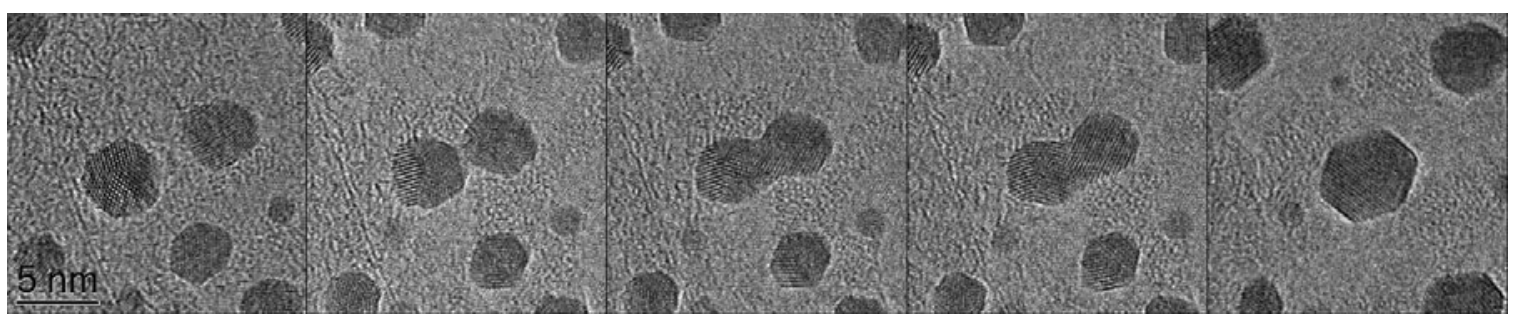

Figure 5. Gold nanoparticles supported on graphene. Each image is extracted from a movie acquired over ca. 2 min in $200 \mathrm{~Pa}$ hydrogen at $100^{\circ} \mathrm{C}$. The images are acquired at $0,55,56,58$, and $94 \mathrm{~s}$, respectively.

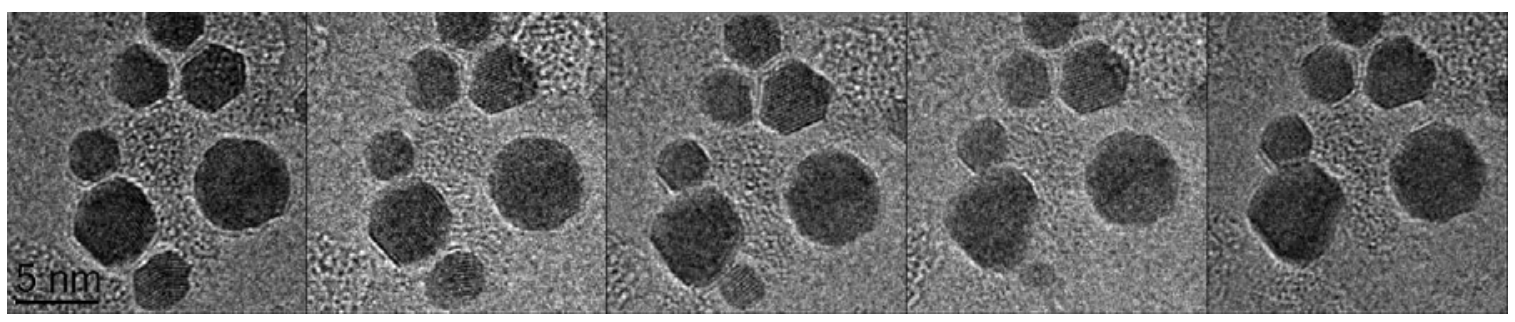

Figure 6. Stills from an image sequence recorded at $400^{\circ} \mathrm{C}$ in $200 \mathrm{~Pa}$ hydrogen. The lower particle gradually decreases in size while the neighboring larger particle grows in size. The images are acquired after $0,13,42,46$, and 48 s, respectively.

In Figure 6, stills extracted from an image sequence recorded at $400^{\circ} \mathrm{C}$ in $200 \mathrm{~Pa}$ of hydrogen are shown. The lower particle in the images is seen to gradually become smaller and the larger particle located just above it becomes larger indicating a transfer of mass from the smaller to the larger particle. This indicates that the particles under these conditions can grow by Ostwald ripening. Under the same conditions rapid coalescence was also observed. Hence a single growth mechanism cannot be assumed, and presumably the overall coarsening of a nanoparticle ensemble follows multiple routes. A recent study conducted on industrial catalysts has shown that initial sintering follows an Ostwald ripening mechanism (Challa et al., 2011). As the present investigations were done on a model substrate, the adhesion properties of the particles can be different giving rise to different sintering mechanisms.

Even though the experiment is heavily prone to beam effects, fundamental growth mechanisms can be observed. More importantly, the aberration-corrected microscope gives access to directly interpretable images of nanoparticles.

\section{Conclusions}

Even though electron intensity is lost when there is a gas in the objective lens, full advantage can still be taken of the benefits of aberration correction. Light molecules such as hydrogen and helium only have small effects on the incident electron wave even at relatively high pressures. With heavier molecules, care has to be taken as a large fraction of the intensity will be lost upon passage of the objective lens.

In situ observations show that sintering of supported metal nanoparticles can occur via both particle migration and coalescence and Ostwald ripening. Observations of these mechanisms occurring simultaneously were also made.

In situ observations made under a gaseous atmosphere can provide new insight into materials behavior. However, care has to be taken when conducting such experiments. The presence of the electron beam can seriously affect the observations. However, with the appropriate precautions, new insight into the material can be obtained. 


\section{ACKNOWLEDGMENTS}

The A.P. Møller and Chastine Mc-Kinney Møller Foundation is gratefully acknowledged for its contribution toward the establishment of the Center for Electron Nanoscopy in the Technical University of Denmark. Jörg Jinschek is gratefully acknowledged for assistance, fruitful discussions, and comments.

\section{References}

Borgna, A., Lenormand, F., Garetto, T., Apesteguia, C.R. \& Moraweck, B. (1992). Sintering of $\mathrm{Pt} / \mathrm{Al}_{2} \mathrm{O}_{3}$ reforming catalysts-EXAFS study of the behavior of metal particles under oxidizing atmosphere. Catal Lett 13, 175-188.

Boyes, E.D. \& GaI, P.L. (1997). Environmental high resolution electron microscopy and applications to chemical science. Ultramicroscopy 67, 219-232.

Challa, S.R., Delariva, A.T., Hansen, T.W., Helveg, S., Sehested, J., Hansen, P.L., Garzon, F. \& Datye, A.K. (2011). Relating rates of catalyst sintering to the disappearance of individual nanoparticles during Ostwald ripening. J Am Chem Soc 133, 20672-20675.

Chaudhry, Q., Scotter, M., Blackburn, J., Ross, B., Boxall, A., Castle, L., Aitken, R. \& Watkins, R. (2008). Applications and implications of nanotechnologies for the food sector. Food Addit Contam 25, 241-258.

Creemer, J.F., Helveg, S., Hoveling, G.H., Ullmann, S., MolenBroek, A.M., SArro, P.M. \& ZANdBergen, H.W. (2008). Atomicscale electron microscopy at ambient pressure. Ultramicroscopy 108, 993-998.

De Jonge, N., Bigelow, W.C. \& Veith, G.M. (2010). Atmospheric pressure scanning transmission electron microscopy. Nano Lett 10, 1028-1031.

Flynn, P.C. \& Wanke, S.E. (1974). A model of supported metal catalyst sintering-2. Application of model. J Catal 34, 400-410.

Girit, C.O., Meyer, J.C., Erni, R., Rossell, M.D., Kisielowski, C., Yang, L., Park, C.H., Crommie, M.F., Cohen, M.L., Louie, S.G. \& ZetтL, A. (2009). Graphene at the edge: Stability and dynamics. Science 323, 1705-1708.

Granqvist, C.G. \& Buhrman, R.A. (1976). Size distributions for supported metal catalysts-Coalescence growth versus Ostwald ripening. J Catal 42, 477-479.

Gryaznov, V.G., Kaprelov, A.M. \& Belov, A.Y. (1991). Real temperature of nanoparticles in electron microscope beams. Philos Mag Lett 63, 275-279.

Hampe, W. (1958). Beitrag zur Deutung der anomalen optichen Eigenschaften feinstteiliger Metallkolloide in grosser Konzentration. 1. Bestimmung des Fullfaktors dunner Schichten eines Kolloids Gold-SiO2. Z Phys 152, 470-475.

Hansen, T.W., Wagner, J.B. \& Dunin-Borkowski, R.E. (2010). Aberration corrected and monochromated environmental transmission electron microscopy: Challenges and prospects for materials science. Mater Sci Technol 26, 1338-1344.
Наsнimoto, H. \& Naiki, T. (1968). High temperature gas reaction specimen chamber for an electron microscope. Jpn J Appl Phys 7, 946-952.

Herman, D.S. \& Rhodin, T.N. (1966). Electrical conduction between metallic microparticles. J Appl Phys 37, 1594-1602.

Howe, J.M., Yoкota, T., Murayama, M. \& Jesser, W.A. (2004). Effects of heat and electron irradiation on the melting behavior of Al-Si alloy particles and motion of the Al nanosphere within. J Electron Microsc 53, 107-114.

Rasmussen, F.B., Sehested, J., Teunissen, H.T., Molenbroek, A.M. \& Clausen, B.S. (2004). Sintering of $\mathrm{Ni} / \mathrm{Al}_{2} \mathrm{O}_{3}$ catalysts studied by anomalous small angle X-ray scattering. Appl Catal A 267, 165-173.

Reimer, L. \& Kohl, H. (2008). Transmission Electron Microscopy: Physics of Image Formation. New York: Springer.

Rostrup-Nielsen, J.R. (1983). Catalytic Stream Reforming. BerlinHeidelberg: Springer.

RusKa, E. (1942). Article on the super-microscopic image in high pressures. Kolloid-Z 100, 212-219.

Salata, O.V. (2004). Applications of nanoparticles in biology and medicine. J Nanobiotechnol 2, 3.

Simonsen, S.B., Chorkendorff, I., Dahl, S., Skoglundh, M., Sehested, J. \& Helveg, S. (2010). Direct observations of oxygen-induced platinum nanoparticle ripening studied by in situ TEM. J Am Chem Soc 132, 7968-7975.

Sмiтh, B.W. \& Luzzi, D.E. (2001). Electron irradiation effects in single wall carbon nanotubes. J Appl Phys 90, 3509-3515.

Sychugov, I., Nakayama, Y. \& Mitsuishi, K. (2010). Sub-10 nm crystalline silicon nanostructures by electron beam induced deposition lithography. Nanotechnology 21, 285307.

Tiede, K., Boxall, A.B.A., Tear, S.P., Lewis, J., David, H. \& Hassellov, M. (2008). Detection and characterization of engineered nanoparticles in food and the environment. Food Addit Contam 25, 795-821.

Tsetseris, L. \& Pantelides, S.T. (2009). Adatom complexes and self-healing mechanisms on graphene and single-wall carbon nanotubes. Carbon 47, 901-908.

van Dorp, W.F., Lazic, I., Beyer, A., Golzhauser, A., Wagner, J.B., Hansen, T.W. \& Hagen, C.W. (2011). Ultrahigh resolution focused electron beam induced processing: The effect of substrate thickness. Nanotechnology 22, 115303.

WANKe, S.E. (1977). Sintering mechanism of supported metal catalysts. J Catal 46, 234-237.

Więckowski, A., Savinova, E. \& Vayenas, C. (2003). Catalysis and Electrocatalysis at Nanoparticle Surfaces. New York: Marcel Dekker.

Wynblatt, P. \& Gjostein, N.A. (1975). Supported metal crystallites. Prog Solid State Chem 9, 21-58.

Yaguchi, T., Suzuki, M., Watabe, A., Nagakubo, Y., Ueda, K. \& Kamino, T. (2011). Development of a high temperatureatmospheric pressure environmental cell for high-resolution TEM. J Electron Microsc 60, 217-225. 